\title{
Obstacles for CCS deployment: An analysis of discrepancies of perceptions
}

\author{
Peter Stigson, Anders Hansson and Mårten Lind
}

\section{Linköping University Post Print}

N.B.: When citing this work, cite the original article.

The original publication is available at www.springerlink.com:

Peter Stigson, Anders Hansson and Mårten Lind, Obstacles for CCS deployment: An analysis of discrepancies of perceptions, 2012, Mitigation and Adaptation Strategies for Global Change, (17), 6, 601-619.

http://dx.doi.org/10.1007/s11027-011-9353-3

Copyright: Springer Verlag (Germany)

http://www.springerlink.com/?MUD=MP

Postprint available at: Linköping University Electronic Press

http://urn.kb.se/resolve?urn=urn:nbn:se:liu:diva-73839 
(Running head:) CCS deployment discrepancies

Original article

Obstacles for CCS deployment: An analysis of discrepancies of

perceptions 


\section{Abstract}

The potential for $\mathrm{CO}_{2}$ emission reductions through carbon capture and storage (CCS) is depending on investments that can bring the technology from the current R\&D through to commercial applications. The intermediate step in this development is demonstration plants that can prove the technical, economic, social, and ecological feasibility of CCS technologies. Based on a CCS stakeholder questionnaire survey and a literature review, we critically analyse discrepancies regarding perceptions of deployment obstacles and experiences from early demonstration plants. The analysis identifies discrepancies between CCS policies versus important deployment considerations and CCS stakeholder policy demands. The discrepancy gap is emphasised by lessons from restructured, postponed, and cancelled CCS projects. To bridge this cognitive gap towards proving CCS through demonstration activities, the article highlights policy implications of establishing a broad understanding of deployment obstacles. Attention to these obstacles is important for policymakers and industry in channelling efforts to demonstrating CCS, hence validating the current focus on CCS as a key abatement potential. Under present conditions, the findings question the robustness of current CCS abatement potential estimates and deployment goals as established by policymakers and in scenarios.

Keywords: Abatement potential; Carbon capture and storage; Demonstration; Deployment; Risk; Stakeholder analysis 


\section{Introduction}

In response to anthropogenic climate change, governments have declared a number of policy measures aimed to reduce energy demand, increase the utilisation of renewable energy, develop carbon dioxide $\left(\mathrm{CO}_{2}\right)$ capture and storage (CCS), as well as mitigating greenhouse gas (GHG) emissions other than $\mathrm{CO}_{2}$. $\mathrm{CCS}$ is often referred to as having a large abatement potential and has received much attention by policymakers, business, NGOs, and academia. The Intergovernmental Panel on Climate Change (IPCC 2005), for example, estimate that CCS may represent approximately $15-55 \%$ of the $\mathrm{CO}_{2}$ abatement potential. Other research identify that deployment of CCS in all EU industry sectors could potentially facilitate $20 \%$ of the Union's abatements by 2030 (McKinsey 2008).

One of the most ambitious responses by governments, which was not met, was the G8 aimed for 20 demonstration plants (>1 Mt per year) by 2010 (G8 Energy Ministers 2008). The EU has adopted the goal to inaugurate 12 CCS demonstration ${ }^{1}$ plants by 2015 - also called The Flagship Programme on CCS (European Council 2008).

However, the deployment of CCS is hampered by low technical maturity of individual components as well as the CCS infrastructure - capture, transport and storage. de Coninck et al. (2009b) has pointed out that although some CCS components are currently commercial, most components and the integrated CCS infrastructure are not. This also applies to CCS coupled to power plants and even more so to industrial processes. While a few storage projects have been operational for some time, there is limited knowledge about technology deployment, acceptance, long-term storage potentials and permanence, and potential environmental hazards. The novel aspects of CCS also mean large uncertainties regarding the feasibility and viability of CCS operations, leading to a number of deployment obstacles. There are also a number of investment uncertainties related to public policy support (von Stechow et al. 2011).

Through a questionnaire, literature review and CCS project survey, the article aims to provide insight into perceived and factual deployment obstacles, and suggest resulting policy implications. Hence, the specific purpose of the study is twofold:

\footnotetext{
${ }^{1}$ We define a demonstration plant as a full CCS infrastructure (capture, transport and storage) where the capture rate exceeds $1.5 \mathrm{Mt} / \mathrm{y}$ from a boiler larger than $300 \mathrm{MW}$ (e.g. Brockett 2009)
} 
- identifying industry perspectives on obstacles to engage in CCS research, development, demonstration, and deployment (RDD\&D); and

- $\quad$ analysing discrepancies between these perspectives, literature and experiences from first-mover demonstration projects that have been restructured, postponed, or cancelled (RPC-projects).

\section{Methodology}

To provide updated stakeholder perspectives on CCS policies and investment conditions, we have used a questionnaire to provide quantitative input (Appendix A). The questionnaire was developed within the project 'Support to regulatory activities for carbon capture and storage $\left(\mathrm{STRACO}_{2}\right)$ '. The questionnaire was distributed during 2008 to purposively selected CCS stakeholders and a broader audience through the Climate Change Info Mailing List. ${ }^{2}$ Of the received responses ( $\left.N=58\right) 68 \%$ were from industry, $11 \%$ from public bodies, $7 \%$ from NGOs, $9 \%$ from research institutions, and $2 \%$ from international institutions. Although targeting a wider range of stakeholders, this study focuses on the industry responses as to analyse deployment perspectives of private actors as key investors in CCS RDD\&D. The questions were both closed and open-ended, including reasons for past investments, investment obstacles and risks, policy perspectives, individual actor responsibilities as well as financing and incentivisation. The importance of investor perspectives in policymaking processes has been emphasised in relation to novel climate policies and complex mitigation solutions (Stigson et al. 2009).

To provide a factual overview of how potential obstacles affected investment decisions, we highlight experiences from seven RPC-projects. A literature review provided additional input to the evaluation of the main identified obstacle groups.

While including international experiences, the study leans towards an EU perspective, seeing that the EU is in the forefront of implementing CCS policies and has a clearly defined deployment goal for demonstration projects. Since the pinnacle issue at present is to test CCS technologies and infrastructures to validate technologies and established deployment goals as feasible, the study focuses on a short to medium-term future. Deployment perspectives in the longer-term are difficult to evaluate as neither the nature nor

\footnotetext{
${ }^{2}$ See http://www.iisd.ca/email/climate-I.htm
} 
existence of future emission trading schemes or other carbon price mechanisms beyond 2020 are known

(Figure 1).

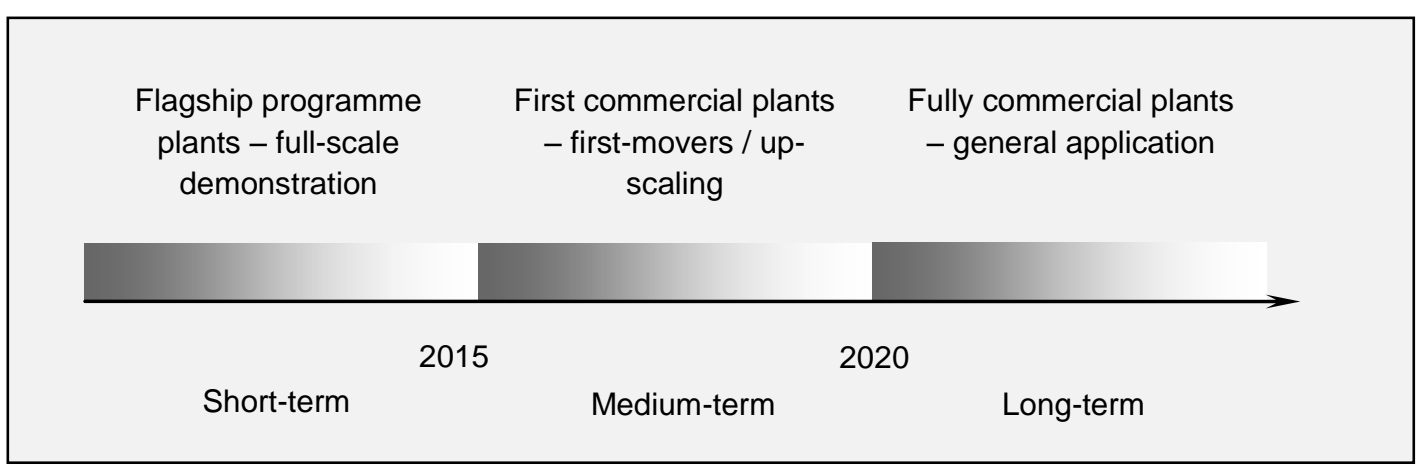

Figure 1 - Schematic time scale for CCS development and policy uncertainty in the EU Note: Years are indicative, based on policy decisions on deployment (e.g. the Flagship Programme) and carbon market trading periods. Source: $\mathrm{STRACO}_{2}(2009)$

\section{CCS deployment obstacles and discrepancies}

This section presents questionnaire results that highlight obstacles for industrial investments and related stakeholder suggestions on how to bridge these obstacles. Mapping the resulting risk profile is important for policymakers as to recognize the main obstacles at present and set priorities for future policy measures. A central part is therefore to highlight that the industry perceptions do not correspond to RPC-projects (Table 1,) and can be challenged by previous research literature as the following analysis will show.

(Table 1)

In general, CCS is associated with large investment risks, which is rooted in the novelty of CCS, policies, infrastructural challenges, large investment costs, and uncertainty regarding storage potential and permanence. The survey results however provide more specific insight into how industry stakeholders perceive obstacles to invest in bringing CCS into a commercial status (Figure 2). 


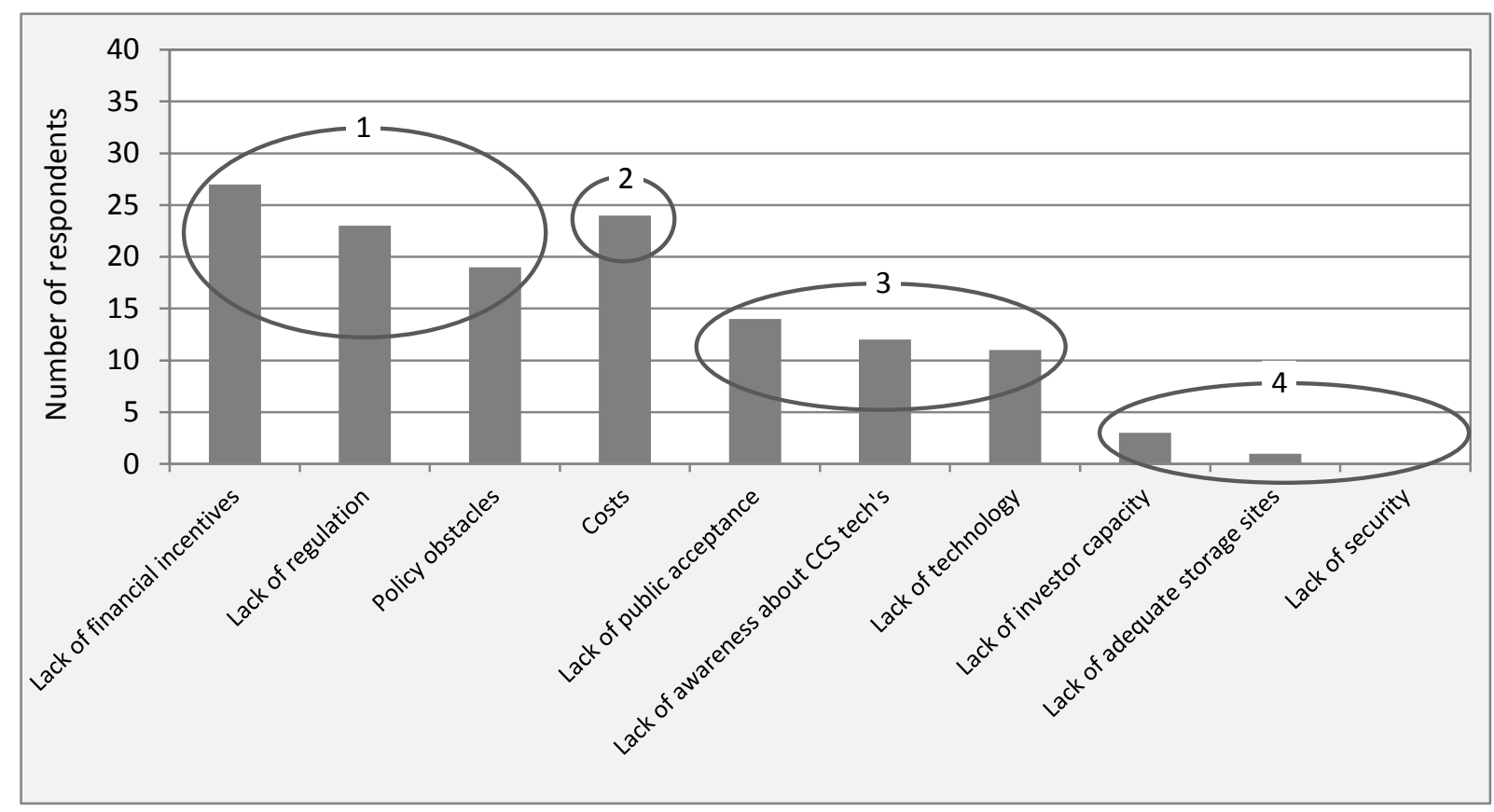

Figure 2 - Which are the biggest obstacles to the commercial success of CCS at the moment? $(N=55)^{3}$

Note: Based on $\mathrm{STRACO}_{2}$ (2009)

The obstacles are in general highly interwoven due to secondary effects, such as the effects on the financial viability of a project of different obstacles/risks. Against this background, the authors have divided obstacles into four categories to provide a broad basis for the analysis. Category 1 specifically relate to policies. Category 2 is exclusively related to costs. Category 3 holds three intermediate risks and category 4 are obstacles that pose least worries for the industry. Respondent comments mainly focused on policies and costs. The subsections on acceptance, technology and storage therefore provide less questionnaire results. Johnsson et al (2010) made an international comparison of stakeholders regarding the largest obstacles for CCS implementation. The most significant barriers were economic viability, lack of suitable storage sites, lack of public acceptance and capital costs. Sala and Oltra (2011) focused on expert's attitudes towards CCS in Spain. Risks such as leakage were emphasised. Compared to those studies, our study showed significantly lower relative number of answers related to risks of geological storage and technology.

\footnotetext{
${ }^{3}$ Looking at investor capacity, the situation would most certainly have changed if the respondents had been able to take the full magnitude and consequences of the 2008/2009 financial slump into consideration, which is why we do not analyse this further here.
} 


\subsection{Policy obstacles}

The respondents argue that an incomprehensive policy regime and implemented policies pose important obstacles for investments. This includes arguments such as: "regulatory uncertainty in terms of governance structure, and gap in assigning risks and liabilities"; "long-term stewardship"; and, "accepting liability into the public sector within a reasonable timeframe". Looking at literature, the negative effects of such policy obstacles on the perceived investment risk are clearly supported. Blyth and et al. (2007) and Dinica (2006), for example, identify that a lack of long-term policy stability can increase investment risks and hence reduce investment dynamics. The time perspective of implemented policies is emphasised for CCS, seeing that demonstration investments today are dependent on future policies; i.e. that policies providing a viable business case when the technology is commercialised are crucial drivers for investments in research, development and demonstration.

Looking at the pinnacle obstacle - a lack of financial incentives - there is a consensus that governmental financial support is required to push CCS from pilot-scale operations (such as Vattenfall's Schwarze Pumpe project in Germany) to larger and full infrastructure demonstration-scale operations. Current and past price levels on the carbon markets are not seen as providing enough financial support to work as an effective incentivisation mechanism at this stage.

Suggestions by the respondents on how to overcome policy obstacles and facilitate investments in CCS technologies mainly focused on how policies influence risks in terms of costs (Section 3.2) and liability. A highlighted issue was how policymakers can bridge the obstacle of price uncertainties on the carbon market. This resulted in suggestions to amend emission trading schemes (Section 3.2). In terms of targeting specific technologies and whether any specific CCS technology is favoured over the others, a respondent argued "No, and that should stay like that. Results should be gained by fixing rules, not by subscribing technology".

Other requirements placed on policymakers included adopting policies and implementing policy decisions more rapidly. One questionnaire reply included "Create the market!" and "provide a framework within which investors can work". Another argument was that the "lack of regulations" means that present planning proposals and approvals "will never be granted without extended public enquiries". 
The respondents also asked for more certainty of the terminology used in policies, where terminology in the draft and final EU CCS Directive, such as "overwhelmingly", "indefinite future", "significant risk of leakage", and "safe storage", was seen as contributing to an increased risk to engage in CCS. While this has been tended to by guidance documents (European Commission 2011), it provided an obstacle until tended to.

\section{Deployment project experiences: Killingholme and Kingsnorth}

The Killingholme IGCC and CCS project were announced by E.ON in 2006 as part of a business plan to engage the company in the development of CCS (E.ON 2008). The project was however postponed due to the UK government decision to exclude pre-combustion from its CCS technology competition (James 2008). E.ON decided to cancel its CCS demonstration plans at Kingsnorth, pulling out of the UK CCS competition entirely. A chief executive said, among other things, that "economic conditions are still not right for us to progress the project", which points at a remaining high policy uncertainty for CCS (Carbon Capture Journal 2010).

\subsection{Costs}

Costs as an investment obstacle were mainly related to capital and operational expenses, which are a natural impediment for investments in CCS as deployment costs are typically significant. Cost estimates for demonstrating CCS commonly are in the range of $€ 40-90 / \mathrm{tCO}_{2}$ (McKinsey 2008, IEA 2008, ZEP 2011). Another group of comments concerned risk premiums related to policies, meaning that the policy risk increases the carbon price needed to support investment. 


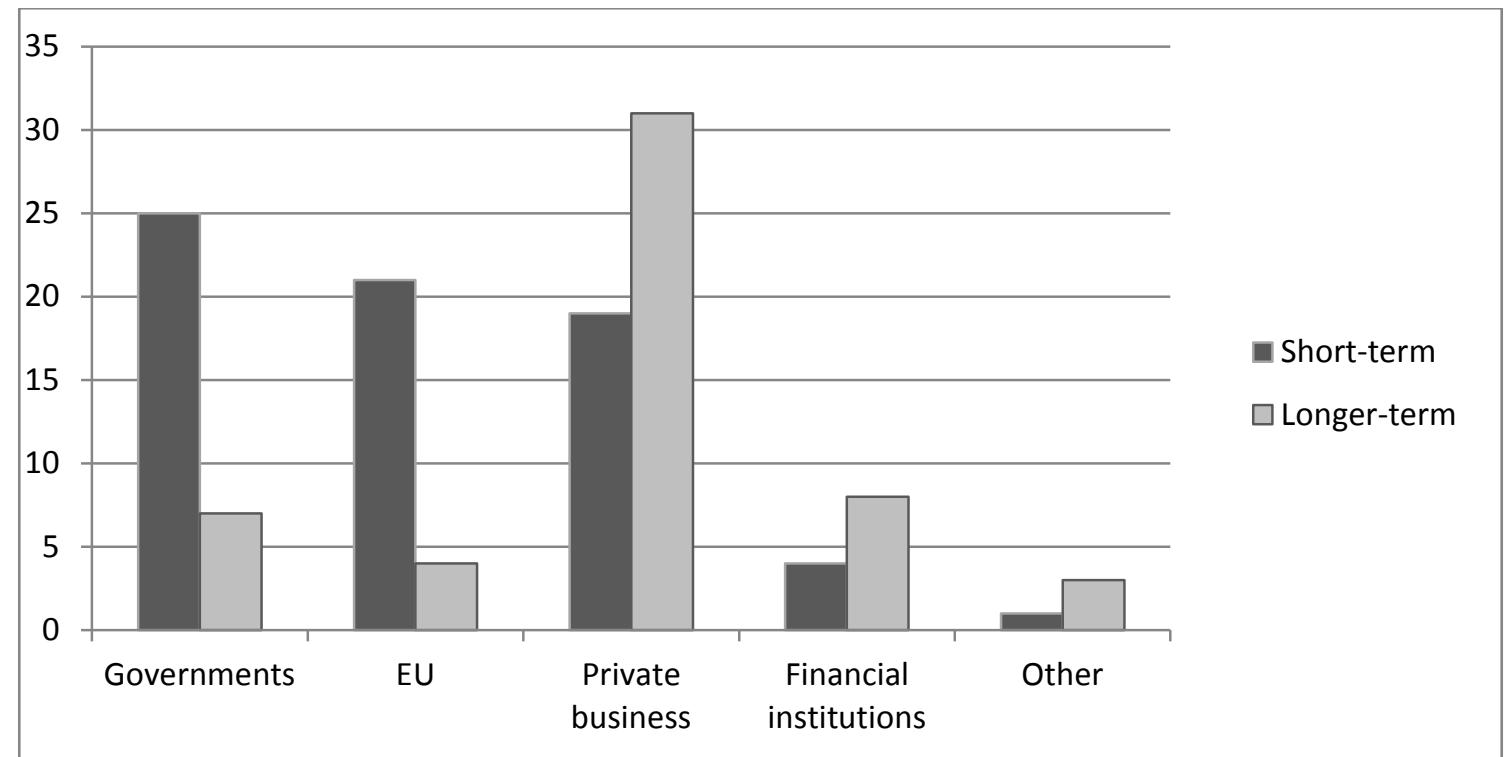

Figure 3 - Industry stakeholder views on financers of CCS in the short and longer-term ( $N=39)$. Source:

$\mathrm{STRACO}_{2}$ (2009)

These obstacles can be alleviated through different mechanisms and the questionnaire respondents from industry emphasise the role of governmental funding in the short-term (Figure 3), implying that the private sector will not engage in demonstration projects alone. As a specific policy response, the respondents highlight short-term subsidies that carry a large share of the construction costs: e.g. "Support for large scale demonstration projects is vital to deployment and commercialization of technology within the next few years". No respondents however suggest how to raise the funds for such purposes. Some respondents specifically highlight a role for governments in supplying a high-share public funding to initial and costly infrastructure solutions, which mainly relates to EU third-party access rules that would benefit subsequent projects. This perspective is shared by Chrysostomidis and Zakkour (2008), who argue that the first-mover benefits of transport projects is potentially small in relation to the financial risks, as full capacity usage cannot be guaranteed.

In a longer-term perspective, $44 \%$ of the industry respondents see joint public and private financing as important and respondents specifically ask for public-private partnerships (PPPs) both in terms of fundraising and as a vehicle to reduce the cost-risk and other risks. A continuous role for governments is argued to lie in implementing long-term policies which supply stable incentives that mitigate investment 
risk, as well as a continuous support for RD\&D on new technologies and improvements of commercial technologies. One respondent clarifies this position by asking for governmental votes on CCS expenditures to provide increased clarity and plausibly stability. Rai et al (2010) also emphasise the importance of governmental support, however claiming that the support is emerging slowly.

The main economic policy instrument discussed by the respondents was emissions trading and the EU-ETS. The current trading schemes were seen as insufficient both in bridging short-term costs as well as providing stable incentives for a sound business case in the long-term. Suggestions to improve the situation take stock of the carbon markets' inherent uncertainties and aim to alter the design of the EU-ETS in relation to CCS as to increase the stability and financial support. This includes: a "fixed carbon price"; "[emission allowance] auctioning revenue recycling"; and, introducing minimum price levels or price premiums on emission rights.

Other suggestions by the respondents on how to overcome the cost and cost-policy obstacles to invest in CCS technologies include: "provide generous financial incentives for demonstration plants"; "establish a large fund today to incentivise the first set (10+) of demonstration projects"; and, "[provide] risk financing for first-movers".

\section{Deployment project experiences: FutureGen and Halten $\mathrm{CO}_{2} \underline{\text { Project }}$}

The FutureGen project was initiated as a PPP in 2003 with the aim to develop a coal-fired IGCC plant that would showcase CCS and coal-to-hydrogen technologies. The project partners were the US Department of Energy (DOE) and an alliance of 12 US and non-US private stakeholders. The DOE was to cover the estimated project budget of $\$ 1$ billion to $74 \%$, including foreign co-financing ( $\$ 10$ million), and the alliance were to supply the remaining $26 \%$. The DOE withdrew from the project after the site selection and shifted position in favour of a restructured FutureGen project (FutureGen 2007). The reason was that the cost estimate for carrying out the initial project almost doubled ( $\$ 1.7$ billion), as costs of "construction materials and equipment, labour, and other heavy construction expenses /.../ significantly increased" (Department of Energy 2007). This was largely a result of price hikes for cement and steel as well as inflation. The DOE's decision was criticised by the House of Representatives to impede investments in CCS RDD\&D (Carbon Capture Journal 2008). Noteworthy is that the project since was resurrected in 2009 only to be restructured again in 2010 (Department of Energy 2010). 
The feasibility study for the Halten $\mathrm{CO}_{2}$ project, a power production and CCS project at Tjeldbergodden in Norway, was initiated in 2006. The project's objective was to erect a gas power plant with CCS and Enhanced Oil Recovery (EOR). Following a one-year feasibility study, the project participants - Statoil and Shell - found that while the project was technically feasible, it did not provide a financially viable business case. The main investment obstacles faced in this case were that the EOR construction costs was too high, while return of EOR was too low, as well as requiring a year-long platform shutdown during construction (Statoil 2007).

\subsection{Acceptance}

The questionnaire results indicate a difference between the industry respondents' views on storage concerns and what the respondents believe might be the public response on CCS. The respondents' concerns regarding storage issues were very low, while the concern regarding a lack of public acceptance was significantly higher. A large number of acceptance studies on CCS have been carried out in specific countries and regions. These studies have been conducted through qualitative interviews, surveys and focus groups. The public's lack of knowledge or awareness on CCS has been repeatedly found, as well as problems like a relative minor support for CCS compared to renewable energy and NIMBY-tendencies (i.e. "not in my backyard"). Of the laymen in acceptance studies conducted in different countries generally 4-22 \% has heard of CCS (Anderson et al. 2007; Reiner 2008). Hence, it is a methodological challenge to elicit public opinions regarding CCS. One recognised pitfall is that surveys may capture so called pseudo-opinions which are unpredictive and easily changeable (de Best-Waldhober et al, 2009). However, the issues that most commonly raise highest concern among lay persons are generally related to environmental risks, storage and leakage - risks that were ranked as low by the respondents in this study (Wallquist et al 2010). Experiences from on-going or postponed storage projects also indicate that the public opinion can turn out to be a major obstacle. The controversies can arise because of diverging valuation of risks as they are based on different perspectives. Generally the laymen's is based on a subjective/constructivistic risk perspective and the industry's is based on an objectivistic. In order to manage constructivistic risk issues participatory processes are needed - an issue we return to in section 4.2 (Anderson et al. 2007; Hansson 2008; Reiner 2008). 


\section{Deployment project experiences: Vattenfall's CCS project Northern Jutland Power Station}

In connection to a coal-fired power plant in northern Jutland, Denmark, Vattenfall has plans to build a $\mathrm{CO}_{2}$ capture facility and store the $\mathrm{CO}_{2}$ in a nearby geological formation called Vested. When the project was announced in February of 2008, the plan was to have it up and running by 2013 (Vattenfall 2008). However, in 2009 the project ran into local opposition. When Vattenfall was to conduct the seismic investigations, local estate owners denied Vattenfall access to their land. This has resulted in Vattenfall postponing the project for at least 2 years (a revised application was sent to the Danish Energy Agency in March 2010). In a Danish newspaper one of the landowners, Asger Møller, who has become a spokesperson for the local opposition, claims that CCS is "risky" and "unknown". He specifically points at uncertainties related to health, the environment and farming as well as the potential negative effect on the value of property (Berlingske Tidene 2009). In a company newsletter, Vattenfall's CCS manager, Bjarne Korshøj, has said “my biggest challenge is to bring about political and local acceptance of CCS" (Vattenfall 2009).

\subsection{Technology}

Advocates for CCS often state that CCS is a "proven technology" (ETP ZEP 2007). Therefore it is not surprising that the industry respondents in this study do not consider a "lack of technology" (Figure 1) as an obstacle for the commercial success of CCS. However, there are reasons to be concerned as the few CCS facilities in operation today are fairly small and uncomplicated compared to what would be the case when implemented at a large-scale coal-fired power plant. A development strategy towards large-scale introduction of $\mathrm{CCS}$, including the integration of $\mathrm{CO}_{2}$ capture with power, heat, cement, refinery, steel and pulp and paper industries, should therefore be prepared to handle a multifaceted range of potential obstacles.

While cost is seen as a major obstacle, costs are expected to decrease with learning. Since much of the learning is expected to take place in $\mathrm{CO}_{2}$ capture, which is the most costly part of the CCS chain, it was interesting to note that most respondents (20 out of 37) thought that no capture technology was favoured over the others. Nevertheless, several respondents had specific comments about the UK competition which they perceived as negative due to a focus on post-combustion technology. In this context, Watson (2008) identifies a trade-off between avoiding picking winners and having a limited R\&D budget. While many 
nations may not have the capacity to go for all technical options and time may be too limited, Watson (2008) refers to several historical examples where winner-picking has been successful.

The $\mathrm{CO}_{2}$ stream composition is an important parameter when designing CCS systems. Impurities such as SOx, NOx, oxygen and moisture may cause damage to infrastructure and have negative effects on environment and/or human health. Early proposed designs of the oxyfuel process had high levels of impurities in comparison with the post- and pre-combustion alternatives, and problems were therefore anticipated (Gale, 2009). Research and development is now underway to find $\mathrm{CO}_{2}$ treatment processes and solutions to remove the impurities, but the problem remains one of the main feasibility challenges for the oxyfuel technology (Kownatzki and Kather 2011; Simonsson et al. 2011). Moreover, the post-combustion absorption option is also problematic. da Silva et al. (2009) conclude that no solvent proposed so far is a "general improvement" compared to the conventional monoethanolamine (MEA), which is associated with several problematic properties. Toxicity is a significant obstacle and in combination with the difficulty in assessing the toxicity as well as considering its potential environmental damage when CCS is introduced large-scale, post-combustion $\mathrm{CO}_{2}$ capture is problematic. In a life cycle analysis of a coal fired power plant with CCS, Koornneef et al. (2008) show that the human toxicity increases with $181 \%$ compared to a reference case without CCS, and concludes that the acceptability of such a trade-off needs to be debated publically.

\section{Deployment project experiences: ZeroGen}

The Australian ZeroGen project was initiated in 2006 and planned to be inaugurated as a full-scale IGCC and CCS project in 2010. During the feasibility study it was however decided to restructure the project and divide it into a demonstrational and a commercial part. The main reason for the two-stage approach was to minimise technology related project risks (ZeroGen 2008). At the same time the expected deployment dates were postponed.

\subsection{Storage}

In this study, no respondent thought a lack of security was an obstacle and only four thought a lack of adequate storage sites may act as a major obstacle. This contradicts storage as including a wide range of 
activities that consume resources and involve risk. Before injection there are a number of activities that take time and resources, from environmental impact assessments and site characterisations to site certifications. During the injection phase other obstacles and risks arise. The risk for leakage is highest during initial stages when injection begins, which has to do with the large pressures involved (IPCC 2005). After injection of $\mathrm{CO}_{2}$ there is disagreement on how to manage it. There are those who say that the natural scientific uncertainties regarding leakage rates likely will remain high for a long time to come and that leakage rates above $0.5 \% /$ year would still be climatically and economically acceptable (van der Zwaan and Gerlagh 2009). Others argue for monitoring and other security measures and say leakage is unacceptable (Ha-Duong and Loisel 2009).

Low concerns for storage is further supported by the results on a specific question $(\mathrm{N}=33)$ regarding the industries' views on how they estimate the storage potential in the EU, where $33 \%$ identified the potential as abundant, $48 \%$ as enough, $3 \%$ as scarce, and $15 \%$ had no opinion. One respondent argued that the potential is enough for the first stage deployment and that the knowledge will build up in time. Although there are reasons to believe that good storage sites may, if well managed, hold $\mathrm{CO}_{2}$ long enough to deliver a climate benefit, there are concerns before, during, and after injection.

In the EU-FP6 project, ACCSEPT, geological storage was highlighted as one of the issues that need more research (Anderson et al. 2007). The storage estimates made until 2007 were claimed to differ by a factor 30 for the very same storage site depending on the methodology used. The higher estimates were considered to be too optimistic and several of the potential storage sites are located too remotely to be considered as realistic storage options. The GeoCapacity project uses conservative estimates and claim that the storage capacity in Europe is $117 \mathrm{GtCO}_{2}$, which corresponds to 62 years of storage of the yearly point source emissions (Vangkilde-Pedersen et al. 2009).

\section{Deployment project experiences: Kwinana}

In 2007 Hydrogen Energy (BP and Rio Tinto) announced the Kwinana CCS project in Australia. The project aimed to capture $\mathrm{CO}_{2}$ from a newly constructed coal-fired IGCC operation with nearby offshore storage. As the feasibility study found the planned storage to be unreliable due to the presence of gas chimneys in the geological strata, the Kwinana was cancelled due to a lack of suitable storage (Foley and Gismatullin 2008). 


\section{Discrepancies and policy implications}

The previous section highlights a number of discrepancies between respondent perceptions, literature, and evidence from the selected RPC-projects. These discrepancies have implications for policymakers in that deployment obstacles pose a threat to, inter alia, the accomplishment of established CCS demonstration deployment targets and evaluating the use of public funds for CCS technology development.

This section will highlight and discuss the discrepancies as well as resulting policy implications. The section builds on the questionnaire results, RPC-projects and literature and includes:

- $\quad$ Costs and policies

- Acceptance

- Technology

- Storage

The discrepancies are of such nature that they may be a direct result of the high expectations of the respondents when it comes to CCS, which is common for innovation processes in general (Brown et al., 2003). CCS deployment goals and estimates of future potential have specifically been criticised for being overly optimistic (Hansson and Bryngelsson 2009). High expectations fill several purposes and Brown et al. (2003), for example claim that expectations can mobilise the future into the present and thus be both constitutive and performative. That is, they form a real-time purpose in the present activities and planning, and they may justify, incite or block a specific development path. Furthermore, expectations are constitutive in the sense that they inflate promises in order to get attention to a particular object. The risk of disappointment, however, is prevalent. Also, as Wilson et al. (2008) point out: "We need to do this right" because a single major accident anywhere in the world due to inadequate regulatory frameworks may endanger the global development of CCS.

\subsection{Bridging the cost gap}

The low technical maturity of CCS imposes a large cost gap between CCS and non-CCS operations. Without robust results from demonstration projects, cost estimates are difficult and costs may be underestimated 
(Anderson et al. 2007). Two examples of problems occurring from this situation are the FutureGen and Halten projects where high costs and unreliable cost estimates resulted in the projects to be restructured and cancelled. Another example is the postponement of the Killingholme project, which points to the challenging viability of CCS demonstration and that government support is important, if not essential, for their deployment.

Designing policies aimed to bridge the cost gap and mitigate the cost-risk must consequently be sensitive to high capital costs and uncertain economics of deploying and operating both whole CCS infrastructures as well as individual components thereof. Also, capture, transport, and storage all have different capital and operational cost-characteristics as well as investment risk profiles. As different policy instruments have different capabilities to bridge different costs, i.e. aiding construction through reducing capital expenses or establishing a business case through creating operational revenues, designing a single policy instrument to work both as the financing and incentivisation mechanism may prove difficult.

In handling short and long-term cost obstacles there will be a need for both public and private RDD\&D funding and incentives. In the short-term, the respondents primarily ask for financing policies, such as subsidies, and the importance of financing outranks financial incentives. The reason is the need for demonstration and that these operations will not face commercial market terms, i.e. requirements to produce positive revenue. In both the short and longer-term, incentives are however required to establish a potential business case (i.e. providing potential revenue). The typical incentive policy is an instrument which establishes a carbon price.

The industry is reluctant to move beyond pilot-scale plants with present policies, meaning that the governments may be forced to estimate and assume significant costs and liability risks for demonstration facilities. This can be related to Halten project stakeholders who have argued that substantial public support for the CCS application could have bridged the cost-risk (StatoilHydro 2007). Halten is one example, which has since been followed by other examples of projects that have diverged from their initial plans due to a lack of supporting policies. The Halten project experience is however important and emphasised as it failed despite a period of extreme oil prices and a CCS friendly policy environment, such as the Norwegian. 
The questionnaire survey results indicate that PPPs can be used to share cost-risks in financing CCS in the shorter-term (i.e. demonstration plants; Figure 3). This was supported by the European Commission (2008), who has argued that PPPs channelling EU Member States' budgets and private investments was the only sources for funding demonstration plants in the EU. The EU has however later channelled support through the EU-ETS and the NER300 programme, supporting renewable energy and CCS innovations. In an international CCS perspective, the success of PPPs is however mixed. The Norwegian Snøhvit has been partly funded via a PPP where the government slowly pulls back from the consortium as investors come in. While this supports the value of PPPs, it should be interpreted from the context of a progressive business sector and government CCS agenda. Failed PPPs in a CCS context can, for example, be found in the FutureGen project. Nonetheless, against the EU situation and industry requests for PPPs, it is recommended that such strategies are considered; bearing in mind both positive and negative experiences.

In a discussion on policies aimed to bridge cost issues, it is worth mentioning that policymakers (e.g. Kougionas 2009), respondents and literature all have a strong focus on emissions trading as the main driver both for demonstration plants and commercial applications. This presents a number of obstacles. Firstly, the literature identifies emissions trading schemes as ineffective in promoting technology development (e.g. Groenenberg and de Coninck 2008; Jepma and Spijker 2008; Odenberg et al. 2008; Otto et al. 2008; Watson 2008). Secondly, prices on the carbon market are today much lower than deployment costs. In a longer-term, return on investments are highly uncertain as the future of international emissions trading is presently unknown and the possibilities for predictable carbon prices hence impossible when CCS is predicted to become commercial (around 2020, see Figure 1). Thirdly, cost-risks are elevated as that the carbon emission price has a risk premium due to the uncertainties on the carbon markets (Blyth et al. 2007), and that the potential for storage capacity scarcity establishes a shadow price in investment and operational calculus (Narita 2009). This means that even though the carbon price would eventually match the costs of CCS operations, theoretically making CCS a financially viable abatement option, the price would need to be significantly higher to work as an effective incentive for investments. This is likely to prolong the time-period of when carbon markets may develop the stringency required to sustain the carbon prices necessary for an effective incentivisation of CCS. Fourthly, cost-risk perceptions in literature also depends on, inter alia, the fluctuations on the fuels and commodities markets (such as coal and steel for constructing 
capture and transport facilities), which is often overlooked (Bazilian and Roques 2008, de Coninck et al. 2009a). In some cases the risks also depend on the possibilities and uncertain financial return of EOR (e.g. Halten).

\subsection{Acceptance}

While acceptance is seen as a concern for both for policymakers and industries, recent experiences could be argued to indicate that the issue is not appropriately addressed. Reiner (2008) has stressed that it is striking that the allocation of resources to communication is minimal. Anderson et al. (2007) have identified the following key gaps regarding research on CCS and acceptance/communication:

1. Include more countries/regions and changes over time

2. Lack of understanding of the link between the perceptions regarding climate change and support for CCS

3. Better understanding of how different educational materials, communication methods and the importance of the messenger in order to build trust

4. More studies of actual storage projects.

We especially emphasize the need for more focus on the last key gap. Ashworth et al (2009) have addressed this issue in a case study in rural Queensland, Australia, where a demonstration project for IGCC with CCS was announced. Anderson et al (2011) also evaluated a case in Australia in order to explore the characteristics of a community in which the CCS acceptance is achieved with relative ease. Based on these findings they made a few general conclusions and developed some guiding principles; however the outcome of the acceptance is still highly context dependent.

The methodological problems linked to the low awareness of the public and the hypothetical character of CCS bias the results emerging from point 1 and 2. By putting more emphasis on gap number three the awareness and knowledge may increase, but the NIMBY phenomena when an actual project starts may radically change the local public opinions. Hence, it is very important, when possible, to integrate the acceptance research with ongoing storage projects - preferably before they start. Also Pellizzoni (2003), 
who has studied the implications of radical uncertainty ${ }^{4}$ on participatory technology assessment (PTA), claims that when values, perspectives and facts are controversial, the only opportunity for mutual understanding is to look for local and practical answers that are based on positional insights. Pro-activity is therefore preferable for several reasons. The evaluation of Vattenfall's storage project at Jutland in Denmark, which encountered local protests, indicates that the communication work has to be started as early as possible (Grönkvist et al. 2010). Furthermore, the communication has to be characterized by transparency, easily accessible information as well as close and early cooperation with environmentally concerned locals. This work has to be very flexible in order to make project adjustment as the demands from the public change. It is also important that the dialogue is nuanced and open for all kinds of perspectives and that the expert perspective does not dominate. Pellizzoni (2003) add that it is important that the process also include an openness to define the problems (e.g. if CCS is necessary at all) and that all kinds of concerns may be addressed.

\subsection{Technology and infrastructural interdependency of capture, transport, and storage}

There is an optimistic view among the respondents on technological obstacles, which aside from potential problems in proving individual technologies can be related to infrastructural challenges of a full CCS system. RPC-project experiences include the ZeroGen project, which has been heavily influenced by the investment risks associated with a novel and advanced technology. This highlights the risks associated with technology uncertainties and costs, where it is not known at the beginning of a long deployment period which the best choice of technology will be.

As mentioned above, the different CCS stages within the full infrastructure are interdependent. This invokes a risk for the operators of each stage from two perspectives. Firstly, any stage within the CCS infrastructure will be unfeasible if the other stages are not available. A logic question for an industry looking to deploy one stage is if someone will supply the other stages. This boils down to the question of who moves first. This concern has also been highlighted by the UK Minister for Energy, Malcolm Wicks (2008), who identifies

\footnotetext{
${ }^{4} \mathrm{CCS}$ is interwoven in a significant complexity with no clear cut scientific answers; environmental tradeoffs, scientific knowledge gaps and externalities that are difficult to valuate (European Commission 2008; Koorneef et al. 2008; Odeh and Cockerill 2008; da Silva et al. 2008).
} 
interdependency as one of the important aspects of deploying demonstration projects, i.e. proving the commercial, contractual, and financial feasibility of full CCS operations. Secondly, as a failure at one stage could bring operations at the other stages to a halt, there is also an operational risk. Both these risks are emphasised in the beginning of developing a robust infrastructure as the system flexibility can be expected to be low. While these risks are relatively easy to mitigate in demonstration project consortia including all systems, it may form an obstacle when it comes to first-movers who will pursue operations at one single stage. The issues should therefore be included on the CCS agenda as not to cause unnecessary uncertainties regarding operational feasibility and respondents views that governmental investments in supplying a transport infrastructure should be remembered.

A freely accessible pipeline system, as is discussed in in the EU, raises the question of whether or not all pipelines should be required to handle also oxy-fuel flue gas. This also raises concerns regarding which capture technologies that potentially can be used in which transport networks, and that early movers may face technology lock-in in capture facilities that do not meet later transport demands on gas composition; pointing to the link between policy and technology obstacles. This perspective should be acknowledged if 'winner-picking' policies are used, meaning that demonstration activities should be coordinated to avoid that the same technologies are picked as 'winners' and that 'winners' are a feasible alternative within the system. Coordination activities similar to the former can be found in the EU.

\subsection{Availability to storage}

While the respondents identify that the general availability of storage is not an obstacle, the Kwinana project have proven that the specific availability at a particular site may be a factual problem. Kwinana experiences thus puts emphasis on geological storage risks in the regional context both in terms of availability and safety. The former (availability) means research should focus on increasing the robustness of regional storage potentials in the context of feasible transportation alternatives. Regional potentials should then be summarised on the international level as to draw up credible deployment scenarios against which policy decisions (e.g. R\&D budgets and subsidies) can be taken. In 2011 the European Commission issued four guidance documents to support the implementation of the CCS directive across the member states. The documents provide a detailed description of how several storage related issues should be 
managed. The documents emphasize the importance of case to case characterizations of potential storage

sites, i.e. there might be a large gap between potential general storage availability and specific availability (European Commission 2011). From the latter perspective (safety) it is interesting to note that a BP representative, in relation to cancelling the Kwinana project, said that as a first of a kind project the involved stakeholders required a very high level certainty of long-term storage safety (Foley and Gismatullin 2008). The situation where a project or region may meet the challenge of lacking storage potential, such as the Kwinana case, will not be inherently mitigated due to increasing technological maturity. Research on storage safety is thus important for validating the long-term feasibility of CCS as well facilitating a viable business case in the demonstration and first-mover phases in the short and medium-term future.

Another aspect when a limited storage capacity may potentially impede the use of CCS is the question of who has the right to utilise this potential. While there is a wide range of alternative/renewable fuels and technologies for abating emissions in connection to heat and power production, as a result of process based emissions that are more difficult to avoid than combustion emissions, CCS provides a significantly more exclusive abatement potential in the steel and cement industries. It is consequently important that policymakers also evaluates to which extent the available potential should be reserved, partly or wholly, for certain operations. Also, this includes a situation where sub-surface space may face competitive interests from other activities (e.g. storage of energy and other gases). The authors therefore recommend that governments provide guidance on the right to use space suitable for $\mathrm{CO}_{2}$ storage.

\section{Discussion and conclusions}

The CCS deployment goals set up by policymakers are at risk. Whether the current EU deployment goal will be fulfilled is uncertain; however the $\mathrm{G} 8$ deployment goal has already been missed. A contributing reason to this development is that a number of vanguard projects have been restructured, postponed, and cancelled due to various deployment obstacles.

This article has set out to contribute to a better understanding of the challenges facing CCS RDD\&D by discussing the following two questions: 1) Which are the main deployment obstacles for testing CCS?; and, 2) Which policy implications do these have? 
In this context, this article highlights that promoting CCS is about reducing a number of risks related to costs, policy, technology, storage, and acceptance. Furthermore, this study identify highly diverse reasons for restructuring, postponing and cancelling projects - more so than the results on industry perceptions of deployment obstacles would indicate. The risks are also often intertwined, which can be exemplified by the Halten project that failed as a combination of poor EOR results, long construction time, and economic viability.

The obstacles discussed in this article are however not necessarily important in all regions and for all CCS projects. Yet, since they have caused vanguard demonstration projects to be restructured, postponed and cancelled, we argue that they should not be overlooked. An important policy implication thus lies in evaluating and considering each obstacle, although each obstacle may not be important in every case.

Ranking one obstacle or discrepancy as more important than another is difficult in light of the RPC-project examples that represent project outcomes that must be considered as adverse for the project stakeholders. However, from the perspective of promoting the investments required to demonstrate CCS, the most important obstacles are logically those that are perceived by industry to pose the largest risks. As such, the lack of a supporting and facilitating policy framework would be seen as the largest obstacle. Nevertheless, a development where obstacles perceived as less risky continue to cause projects to be restructured, postponed and cancelled could shift industry risk perspectives. This implies that demonstration projects should be monitored in terms of how they develop already from the earliest stages in the project cycle (e.g. feasibility studies). In order to facilitate an evaluation of discrepancies, this should be parallel to monitoring how the risk perceptions develop. This information provides relevant and experience-based input to the design of robust policy frameworks that are capable of dealing with the broad set of obstacles facing CCS demonstration stakeholders.

To conclude, the RPC-projects are among the largest initiatives taken and their outcomes point to insufficient knowledge and development in a number of areas to make CCS investments and deployment goals feasible and reliable. These discrepancies should be acknowledged in the on-going international efforts of designing and redesigning policies aimed to effectively promote CCS demonstration activities. 


\section{Appendix A}

Excerpts from STRACO2 questionnaire with questions used in the study described in this article. Full questionnaire is available from the project website at http://www.euchina-ccs.org (Cited 25 Oct 2010).

1) Name of organisation

2) Status of organisation
a) Government
b) International organisation
c) NGO
d) Private business
e) Research institution
f) Other

3) Further use of this questionnaire
a) Answers in this questionnaire may be used for public use
b) Information given in this questionnaire may be used within the STRACO2 project and made public only in aggregated results

4) Which are the biggest obstacles to the commercial success of CCS at the moment? (you can select more than one)
a) Policy obstacles
b) Lack of technology
c) Lack of regulation
d) Lack of financial incentives
e) Lack of investor capacity
f) Lack of adequate storage sites
g) Lack of public acceptance
h) Lack of awareness about CCS technology 
i) Lack of Security

j) Costs

k) Other

5) Do you see potential sites in the EU as
a) Abundant
b) Enough
c) Scarce
d) No opinion

6) Who should take the lead in financing pilot projects and early applications of CCS?
a) Governments
b) The EU
c) Private business
d) Financial institutions
e) Other

7) Please state why?

8) Which stakeholders are the most important financers of CCS in a longer term?
a) Governments
b) The EU
c) Private business
d) Financial institutions
e) Other

9) What, if any, problems/barriers exist in the draft CCS directive by the EC?

10) What, if any, problems/barriers exist in the CCS amendments of the EU-ETS directive suggested by the European Commission?

11) What is your view on other regulatory activities in the EU related to CCS? (Synergies, barriers, opportunities etc.)

12) Do you find that any specific CCS technology is favoured by policies (over the others)?

13) If you have invested in CCS activities, what was the main driver? 

a) Present policy regulation
b) Future policy developments (anticipated)
c) Business strategic decisions
d) Research RD\&D
e) Other

14) (For business/finance) What, if any, are the main regulatory (policy) obstacles for investing in CCS technology?

15) (For business/finance) What requirements do you put on policy makers to:
a) Initiate, maintain or increase participation in CCS RD\&D
b) Invest in CCS applications

16) (For business/finance) What is your key message to policy makers in order to promote an increased business interest in CCS activities? 


\section{Acknowledgments}

The authors would like to thank the European Commission and the Directorate General for Research, who under the 7th Framework Programme funded the project Support to Regulatory Activities for Carbon Capture and Storage $\left(\mathrm{STRACO}_{2}\right)$. We would also like to thank the project partners for the cooperation within the project as well as all respondents for their time and effort for returning the questionnaires with detailed replies. Peter Stigson and Anders Hansson would also like to express their gratitude to Mistra for funding within the Clipore project.

The non-cited views and conclusions that are drawn in the article is solely those of the authors and do not necessarily represent those of neither of the project consortia nor any part or individual of the European Commission or Mistra.

\section{References}

Anderson J, de Coninck H, Curnow P, et al (2007) The ACCSEPT project: Multidisciplinary analysis and gapfilling strategies. http://www.accsept.org/outputs/wp_4_november.pdf. Cited 25 Oct 2010

Anderson C, Schirmer J, Abjorensen N (2011) Exploring CCS community acceptance and public participation from a human and social capital perspective. Mitigation and Adaptation Strategies for Global Change. In Press.

Ashworth P, Pisarski A, Thambimuthu K (2009) Public acceptance of carbon dioxide capture and storage in a proposed demonstration area. Journal of Power and Energy. 223:299-304

Bazilian M, Roques F (2008) Analytical methods for energy diversity \& security. Elsevier, Oxford.

Berlingske Tidene (2009) Vattenfalls gigantsatsning lammet.

http://www.business.dk/article/20090802/okonomi/708020066. Cited 25 Oct 2010

de Best-Waldhober M, Daamen D, Ramirez A et al (2009) Informed public opinions on CCS in comparison to other mitigation options. Energy Procedia 1:4795-4802

Blyth W, Bradley R, Bunn D et al (2007) Investment risks under uncertain climate change policy. Energy Policy 35:5766-5773 
Brockett S (2009) The EU enabling legal framework for carbon capture and geological storage. 9th

International Conference on Greenhouse Gas Control Technologies. Energy Procedia 1:4433-4441

Brown N, Rip A, Van Lente H (2003) Expectations In \& About Science and Technology.

http://www.york.ac.uk/satsu/expectations/Utrecht\%202003. Cited 25 Oct 2010

Carbon Capture Journal (2010) E.ON pulls out of UK CCS competition Projects.

http://www.carboncapturejournal.com/displaynews.php?NewsID=665\&PHPSESSID=aqgudbstc2ee ppbevtto3ppfo4. Cited 26 Oct 2010

Carbon Capture Journal (2008) US subcommittee reviews DOE's plans for FutureGen.

http://www.carboncapturejournal.com/displaynews.php?NewsID=199\&PHPSESSID=232. Cited 25 Oct 2010

Chrysostomidis I, Zakkour P (2008) Assessment of the range of potential funds and funding mechanisms for CO2 transportation networks. Draft Report.

http://www.co2captureproject.org/policies_publications.html. Cited 25 Oct 2010

de Coninck $\mathrm{H}$, Flach T, Curnow P et al (2009a) The acceptability of $\mathrm{CO}_{2}$ capture and storage (CCS) in Europe: An assessment of the key determining factors: Part 1. Scientific, technical and economic dimensions. Int J Greenhouse Gas Control 3:333-343

de Coninck H, Stephens JC, Metz B (2009b) Global learning on carbon capture and storage: A call for strong international cooperation on CCS demonstration. Energy Policy 37:2161-2165

Department of Energy (2010) Secretary Chu Announces FutureGen 2.0. Press release: August 5, 2010. http://www.energy.gov/news/9309.htm. Cited 25 Oct 2010

Department of Energy (2007) DOE Signs FutureGen Cooperative Agreement. Press release: April 10, 2007. http://fossil.energy.gov/techline/techlines/2007/07019-DOE_Signs_FutureGen_Agreement.html. Cited 25 Oct 2010

Dinica V (2006) Support systems for the diffusion of renewable energy technologies - an investor perspective. Energy Policy 34:461-480 
E.ON (2008) Carbon, cost and consequences. http://www.eon-uk.com/downloads/Manifesto_Brochure__final_30_05_08.pdf. Cited 25 Oct 2010

ETP ZEP (2007) European technology platform for zero emission fossil fuel power plants (ZEP) - Strategic overview. European Technology Platform for Zero Emission Fossil Fuel Power Plants. http://www.zero-emissionplatform.eu/website/library/index.html. Cited 25 Oct 2010

European Commission (2008) 2020 by 2020: Europe's climate change opportunity. COM(2008) 30 final. http://eur-lex.europa.eu/LexUriServ/LexUriServ.do?uri=COM:2008:0030:FIN:EN:PDF. Cited 25 Oct 2010

European Commission (2011) Implementation of Directive 2009/31 on the Geological Storage of Carbon Dioxide. Guidance Document 2. Characterisation of the Storage Complex, CO2 Stream Composition, Monitoring and Correction Measures.

European Council (2008) Presidency conclusions, European Council, June, 19-20, 2008. http://europa.eu/european-council/index_en.htm. Cited 25 Oct 2010

Foley B, Gismatullin E (2008) BP, Rio Cancel \$2 Billion Australian Power Project. http://www.bloomberg.com/apps/news?pid=newsarchive\&refer=australia\&sid=ag.zXqGzi22g. Cited 25 Oct 2010

FutureGen (2007) Final site selection report (December 18, 2007). FutureGen Industrial Alliance, Inc. http://www.futuregenalliance.org/news/site_selection_report.stm. Cited 25 Oct 2010

G8 Energy Ministers (2008) Joint Statement by G8 Energy Ministers.

http://www.enecho.meti.go.jp/topics/g8/g8sta_eng.pdf. Cited 25 Oct 2010

Gale J (2009) Impure thoughts. Int J Greenhouse Gas Control 3:1-2

Groenenberg H, de Coninck H (2008) Effective EU and Member State policies for stimulating CCS. Int J Greenhouse Gas Control 2:653-664

Grönkvist S, Bryngelsson M, Westermark M (2006) Oxygen efficiency with regard to carbon capture. Energy $31: 3220-3226$ 
Ha-Duong M, Loisel R (2009) Zero is the only acceptable leakage rate for geologically stored CO2: An editorial comment. Clim Change 93:311-317

Hansson A (2008) Kolets återkomst - Koldioxidavskiljning och lagring i vetenskap och politik. Dissertation, Linköping University

Hansson A, Bryngelsson M (2009) Expert opinions on carbon dioxide capture and storage - A framing of uncertainties and possibilities. Energy Policy 37:2273-2282

IEA (2008) $\mathrm{CO}_{2}$ capture and storage. A key abatement option. International Energy Agency, Paris

IPCC (2005) IPCC Special Report on Carbon Dioxide Capture and Storage. Prepared by Working Group III of the Intergovernmental Panel on Climate Change, Metz B, Davidson O, de Coninck HC et al (eds). Cambridge University Press, Cambridge, United Kingdom and New York.

James S (2008) Personal communication. Combustion Technology Team, E.ON Engineering, E.ON UK.

Jepma CJ, Spijker E (2008) Setting the incentives right for timely CCS deployment. Report by the Netherlands Working Group 'Schoon Fossiel' SenterNovem, Utrecht

Johnsson F, Reiner D, Itaoka K, Herzog H (2010) Stakeholder attitudes on Carbon Capture and Storage-An international comparison. International Journal of Greenhouse Gas Control. 4:410-1418.

Koornneef J, van Keulen T, Faaij A et al (2008) Life cycle assessment of a pulverized coal power plant with post-combustion capture, transport and storage of CO2. Int J Greenhouse Gas Control 2:448-467

Kougionas V (2009) EC supported research in carbon capture and storage. Oral presentation at the STRACO2 Workshop on CCS regulation in the EU and China. Brussels, 24 April 2009

Kownatzki S, Kather A (2011) CO2 Purity in Coal Fired Oxyfuel Processes. Proceedings of the 2nd Oxyfuel Combustion Conference, Queensland, Australia, 12-16 September.

McKinsey (2008) Carbon Capture \& Storage: Assessing the Economics. McKinsey \& Company.

Narita D (2009) Economic Optimality of CCS Use: A Resource-Economic Model. Kiel Institute for the World Economy. http://www.ifw-members.ifw-kiel.de/publications/economic-optimality-of-ccs-use-aresource-economic-model/KWP\%201508.pdf. Cited 25 Oct 2010 
Odeh NA, Cockerill TT (2008) Life cycle GHG assessment of fossil fuel power plants with carbon capture and storage. Energy Policy 36:367-380

Otto VM, Löschel A, Reilly J (2008) Directed technical change and differentiation of climate policy. Energy Economics 30:2855-2878

Pellizzoni L (2003) Uncertainty and Participatory Democracy. Environmental Values 12:195-224

Rai V, Victor DG, Thurber MC (2010) Carbon capture and storage at scale: Lessons from the growth of analogous energy technologies. Energy Policy. 38: 4089-4098

Reiner M (2008) A looming rhetorical gap: A survey of public communications activities for carbon dioxide capture and storage technologies. http://www.eprg.group.cam.ac.uk/wpcontent/uploads/2008/11/eprg08012.pdf. Cited 25 Oct 2010

Sala S, Oltra C (2011) Expert's attitudes towards CCS technologies in Spain. International Journal of Greenhouse Gas Control. 1339-1345.

Scrase JI, Watson J (2011) Strategies for the deployment of CCS technologies in the UK: a critical review. Energy Procedia. 1:4535-4542.

da Silva EF, Hoff KA, Svendsen HF (2008) Can we improve upon MEA as solvent for CO2 capture? In: Proceedings of the 9th International Conference on Greenhouse Gas Control Technologies (GHGT9), Washington DC, 16-20 Nov 2008

Simonsson N, Anheden M, Dubettier R, Joly L, Lockwood F, Tranier J (2011) Development Opportunities for Future Large Scale Lignite Oxyfuel Power Plants. Proceedings of the 2nd Oxyfuel Combustion Conference, Queensland, Australia, 12-16 September.

Statoil (2007) Halten CO2 verdikjede: Teknisk mulig, men ikke kommersielt gjennomførbar. http://www.statoil.com/no/NewsAndMedia/News/2007/Pages/HaltenCO2ValueChain.aspx. Cited Oct 2010

StatoilHydro (2007) Sustainability Report 2007. http://www.statoilhydro.com/en/environmentsociety/sustainability/2007/pages/default.aspx. Cited 12 Nov 2008 
von Stechow C, Watson J, Praetorius B (2011) Policy incentives for carbon capture and storage technologies in Europe: A qualitative multi-criteria analysis. Global Environmental Change. 21:346-357

Stigson P, Dotzauer E, Yan J (2009) Improving policy making through government-industry policy learning: The case of a novel Swedish policy framework. Appl Energy 86:399-406

STRACO $_{2}$ (2009) Support to regulatory activities for carbon capture and storage: Final report. http://www.euchina-ccs.org. Cited 25 Oct 2010

Vangkilde-Pedersen T, Lyng Anthonsen K, Smith N et al (2009) Assessing European Capacity for Geological Storage of Carbon Dioxide. Energy Procedia 1:2663-2670

Vattenfall (2008) Factsheet CCS. http://www.vattenfall.com/www/co2_en/co2_en/Gemeinsame_Inhalte/DOCUMENT/388963co2x /578173repo/1476055fac/P0278297.pdf. Cited 26 Oct 2009

Vattenfall (2009) Bridging to the future. Newsletter on Vattenfall's project on carbon capture and storage. No. 13. http://www.vattenfall.com/en/ccs/newsletter-online-2009---may.htm. Cited 25 Oct 2009

Wallquist L, Visschers VHM, Siegrist M (2010) Impact of Knowledge and Misconceptions on Benefit and Risk Perception of CCS. Environ Sci Technol 44:6557-6562.

Watson J (2008) Setting Priorities in Energy Innovation Policy: Lessons for the UK. Discussion Paper 2008-07. John F Kennedy School of Government, Harvard University.

Wicks M (2008) CCS - the next step. Carbon Capture Journal 5:2

Wilson EJ, Morgan MG, Apt J et al (2008) Regulating the Geological Sequestration of CO2: As greenhouse gas emissions rise and the impacts of climate change grow, the need for safe and effective $\mathrm{CO} 2$ capture and sequestration becomes ever more urgent. Environ Sci Technol 42:2718-2722

ZEP (2011) The Costs of $\mathrm{CO}_{2}$ Capture, Transport and Storage. Zero Emissions Platform.

ZeroGen (2008) ZeroGen Project reconfigured. Press release: March 20, 2008. http://www.zerogen.com.au/cms/news/Default.aspx?NewsCode=150. Cited 25 Oct 2010 
van der Zwaan B, Gerlagh R (2009) Economics of geological CO2 storage and leakage. Clim Change 93:285-

309 
Figure legends:

Figure 1 - Schematic time scale for CCS development and policy uncertainty in the EU Note: Years are indicative, but based on policy decisions on deployment (e.g. the Flagship Programme) and policy decisions establishing carbon markets.

Figure 2 - Which are the biggest obstacles to the commercial success of CCS at the moment? $(\mathrm{N}=55)^{5}$

Figure 3 - Main financers of CCS in the short and longer-term

${ }^{5}$ Looking at investor capacity, the situation was expected to have changed if the respondents had been able to take the full magnitude and consequences of the 2008/2009 financial slump into consideration, which is why we do not analyse this further here. 
Tables and table captions:

Table 1 - Restructured, postponed, or cancelled CCS deployment projects

\begin{tabular}{|c|c|c|c|}
\hline Project & Location & Type & Status (update) \\
\hline FutureGen & Illinois, USA & $\begin{array}{l}\text { IGCC, Pre-combustion } \\
(275 / 200 \mathrm{MW})\end{array}$ & Restructured $^{a}$ \\
\hline Halten $\mathrm{CO}_{2}$ Project & $\begin{array}{l}\text { Tjeldbergodden, } \\
\text { Norway }\end{array}$ & $\begin{array}{l}\text { Post-combustion } \\
(850 \mathrm{MW})\end{array}$ & Cancelled $^{\mathrm{a}}$ \\
\hline Killingholme & England, UK & $\begin{array}{l}\text { IGCC, Pre-combustion } \\
\text { (450 MW) }\end{array}$ & Postponed $^{b}$ \\
\hline Kingsnorth & England, UK & $\begin{array}{l}\text { Coal, Post-combustion } \\
(2 * 800 \mathrm{MW})\end{array}$ & Cancelled $^{c}$ \\
\hline Kwinana & Western Australia & $\begin{array}{l}\text { IGCC, Pre-combustion } \\
(500 \mathrm{MW})\end{array}$ & Cancelled $^{a}$ \\
\hline ZeroGen & Queensland, Australia & $\begin{array}{l}\text { IGCC, Pre-combustion } \\
(80 / 300 \mathrm{MW})\end{array}$ & Restructured/Postponed $^{d}$ \\
\hline Northern Jutland & Aalborg, Denmark & Post-combustion & Postponed $^{\mathrm{e}}$ \\
\hline Power Station & & (305MW) & \\
\hline
\end{tabular}

Note: The status of the projects was updated 28 October 2010 (through the links below).

${ }^{\mathrm{a}}$ http://sequestration.mit.edu/

${ }^{\mathrm{b}}$ http://www.netl.doe.gov/technologies/carbon_seq/database/

${ }^{\mathrm{c}}$ http://www.eon-uk.com/

${ }^{d}$ http://www.zerogen.com.au/

${ }^{\mathrm{e}}$ http://www.vattenfall.com/en/ccs/northern-denmark.htm 